\title{
Improving Education Trough Engineering Part II: The Iku/Arhuaco People. Their Science, Culture and Math as a tribute to an existing Latin American and Caribbean Civilization.
}

\author{
M.Eng. Ernesto Vega Janica, Hugues Vega Murgas, PhD. Simón Esmeral Ariza \\ e.vegajanica@ieee.org, huvemu@hotmail.com, simonesmeral@hotmail.com
}

\begin{abstract}
This paper discusses our most recent studies and documented learning experiences related to this existing, PreHispanic indigenous community in the northern region of Colombia, South America. This paper is a simple attempt to raise awareness of the magnificent STEM skills of the Iku (a.k.a. Arhuaco) people, and how they have preserved their knowledge, and applied science in harmony with nature and other civilizations.
\end{abstract}

This paper is also a continuation of the title "Improving Education Trough Engineering: Advanced Native Numerical Systems and their applicability on STEM and Robotics curricula" published by LACCEI 2018 and presented in Lima, Peru in July of 2018.

Index Terms - ancestral knowledge, Arhuaco, ASCII, Aztecs, base 2, base 10, base 20, binary code, calendar, decimal system, Iku tribe, mathematics, Maya, numerical systems, pre-Hispanic, STEM, vigesimal system.
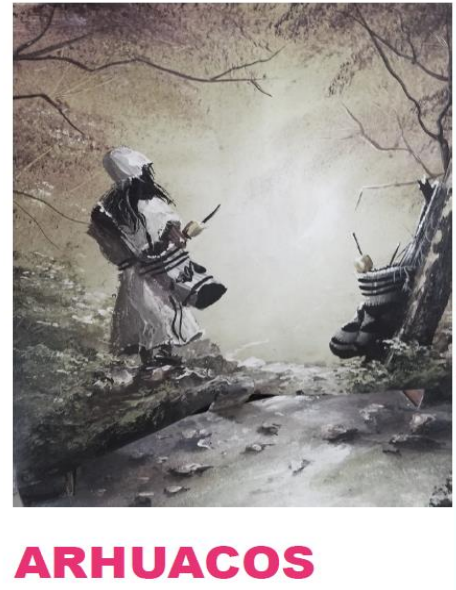
IKU TRIBE

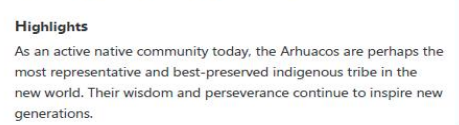

generations.

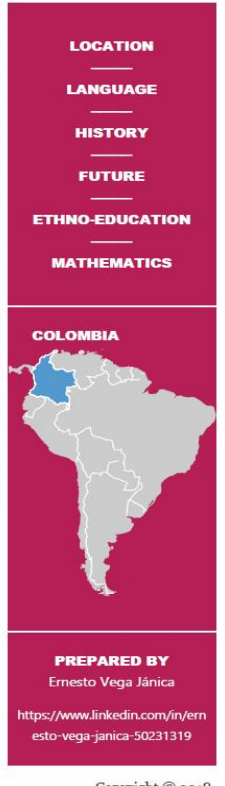

Copyright $\odot 2018$

\section{INTRODUCTION TO THE IKU/ARHUACO TRIBE}

Before beginning the discussion on the numerical and science skills, and how the Arhuacos have implemented such vast knowledge building cities, farming crops and bringing water to remote areas, it is important to mention that the cultural wealth of the Arhuaco people and other indigenous communities should be of great pride for our current and future generations. The study and documentation of their knowledge should be considered as a tool to better understand our relationship with the world around us and our role before nature, science and art.

In the next few paragraphs, we will see some practical and didactic elements that we hope will bring our communities closer to learn, respect and love this indigenous community of the Iku (Arhuacos).
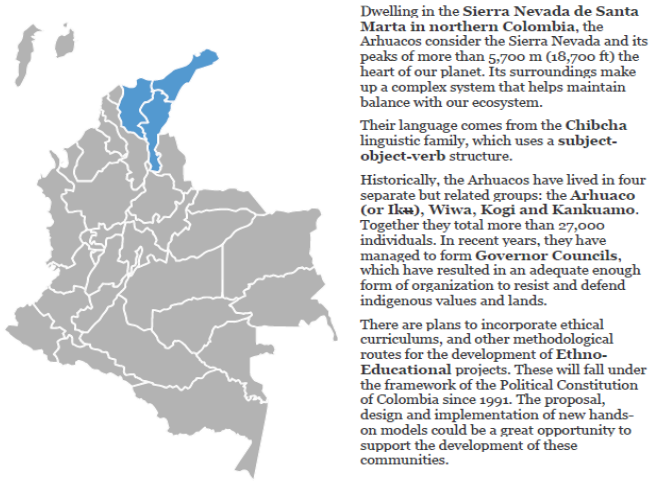

\begin{tabular}{|c|c|}
\hline \multicolumn{2}{|c|}{ Arhuaco Numbers (Pronunciation in Chibcha Language): } \\
\hline 1. (Ingui) & 11. (Ingui uga ingui ketot) o $((1 \times 10)+1)$ \\
\hline 2. (Mouga) & 12. (Ingui uga mouga ketot) $)(((1 \times 10)+2)$ \\
\hline 3. (Maykent) & 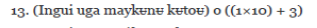 \\
\hline 4. (Ma'keywa) & 14. (Ingui uga ma' keywa kettot) $0(((1 \times 10)+4)$ \\
\hline 5. (Asewa) & 15. (Ingui uga asewa kettö) o ((1×10) + 5) \\
\hline 6. (Chingwa) & 16. (Ingui uga chingwa ketot) $)((1 \times 10)+6)$ \\
\hline 7. (Koga) & 17. (Ingui uga koga ketot) $) \circ((1 \times 10)+7)$ \\
\hline 8. (Abewa) & 18. (Ingui uga abewa kttot) $)((1 \times 10)+8)$ \\
\hline 9. (Ikawa) & 19. (Ingui uga ikawa ketot) o $((1 \times 10)+9)$ \\
\hline 10. (Uga) & 20. (Mouga uga) $0(2 \times 10)$ \\
\hline
\end{tabular}

Fig. 1 Iku's Location and Basic Info [1].

As an active native community today, the Arhuacos are perhaps the most representative and best-preserved

indigenous tribe in the new world. Their wisdom and perseverance continue to inspire new generations.

Digital Object Identifier (DOI):

http://dx.doi.org/10.18687/LACCEI2019.1.1.48

ISBN: 978-0-9993443-6-1 ISSN: 2414-6390 
Dwelling in the Sierra Nevada de Santa Marta in northern Colombia, the Arhuacos consider the Sierra Nevada and its peaks of more than $5,700 \mathrm{~m}(18,700 \mathrm{ft})$ the heart of our planet. Its surroundings make up a complex system that helps maintain balance with our ecosystem. See Fig. 1.

Their language comes from the Chibcha linguistic family, which uses a subject-object-verb (SOV) structure, similar to Korean, Mongolian, Turkish, the Indo-Aryan and the Dravidian languages, and unlike English and most other European languages, which are considered SVO (subjectverb-object) languages.

Historically, the Arhuacos have lived in four separate but related groups: the Arhuaco (or Iku), Wiwa, Kogi and Kankuamo. Together they total more than 27,000 individuals. In recent years, they have managed to form Governor Councils, which have resulted in an adequate enough form of organization to resist and defend indigenous values and territories.

There are also new plans to incorporate more ethnicfocus curricula and other methodological tools for the development of Ethno-Educational projects that could bring access to culturally and linguistically appropriate education tools that do not result in unwanted assimilation; such model(s) could also be a great opportunity to support the development of these communities.

\section{The Science And Technology of the Arhuaco}

The customs and traditions of the Arhuaco people have always been linked to nature and its balance with their environment. The application of mathematical concepts, geometry, architecture, and even astrology, have been broadly used throughout the Sierra Nevada de Santa Marta and its surroundings.

Remarkably, the Arhuacos have built irrigation systems and rainwater managements systems for their plantations, even though these are located in highly steep areas and with limited resources. The construction of stone stairways, retaining walls and plateaus, demonstrate their high knowledge in architecture and engineering. Some even consider the location of the plateaus related to astrology and the crop's grown cycles. Either way, the amount of work, expanded throughout thousands of acres and various climate conditions, is a living example of indigenous creativity and applied science.

Furthermore, the Arhuacos' skills and philosophy is vastly based on their knowledge of the surroundings, its resources and their own limitations, as well as their social interactions and their spirituality. Knowing which trees, rocks, seeds, water and other resources to use, and which ones not to use, is critical for their success.

Other STEM and applied science concepts are used in agriculture, medicine, and engineering. As mentioned earlier, agriculture have reach some advanced progress due to the use of plateaus and irrigation systems, but these improvements also have a positive impact on their economy as the natives now grow coffee and other crops, and even produce some value add products.

Medicine and clothing manufacturing is also another good example of their knowledge in applied science. Arhuacos' main leaders and elders, also known as "Mamos", have master the use of a varieties of healing plants, as well as traditional dying mechanisms that have given them the ability of manufacturing not only medicines but also fabrics, clothing and highly valuable mochilas (or knapsacks). See Fig. 2.

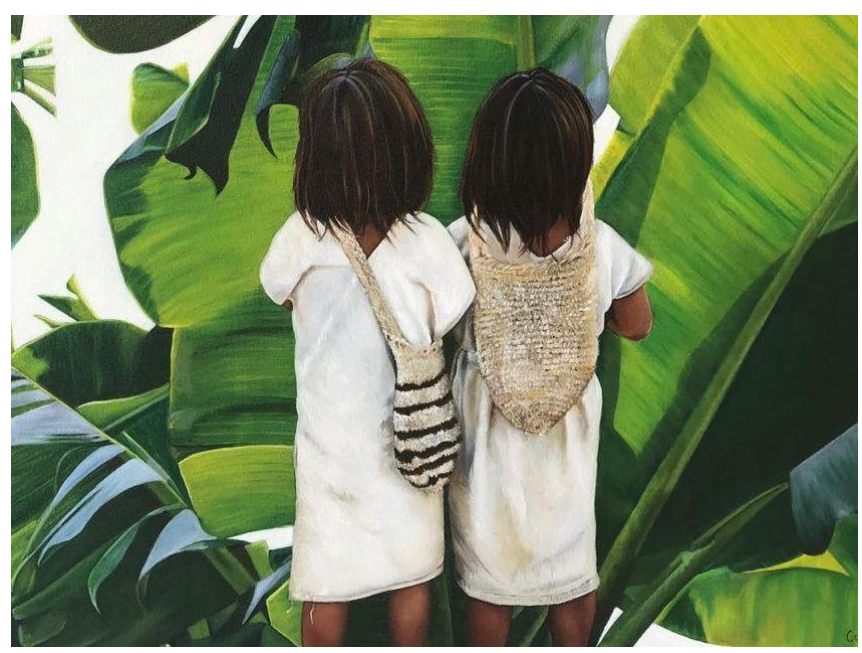

Fig. 2 Arhuaco Kids wearing Mochilas. Oil painting in canvas by Connie Gomez. Used with permission of the Artist.

Thru science they have also managed to create educational programs focused in their cultural and social believes, such as the explanation of eclipses, solar energy and other phenomena are now explained in a more holistic away. See Fig. 3.

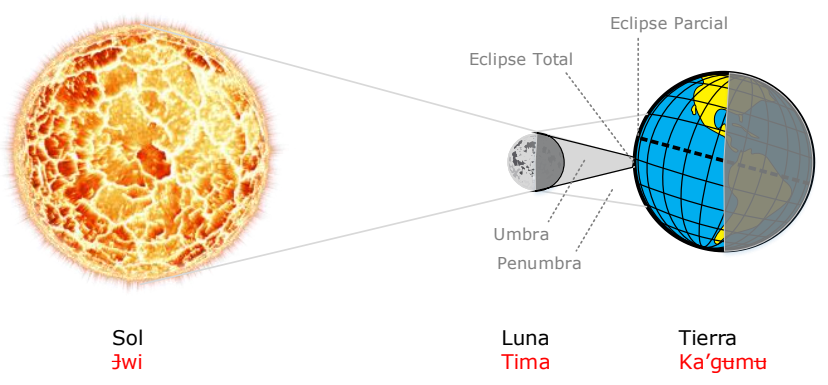

Fig. 3 Examples of Science Concepts now in their Curricula [2].

As a direct result of such educational programs, and probably influenced by interaction with other communities in nearby cities like Santa Marta and Valledupar, the Arhuacos are now implementing solar panels and the use of renewable energy sources in some of their towns and schools (See Concept in Fig. 4). 


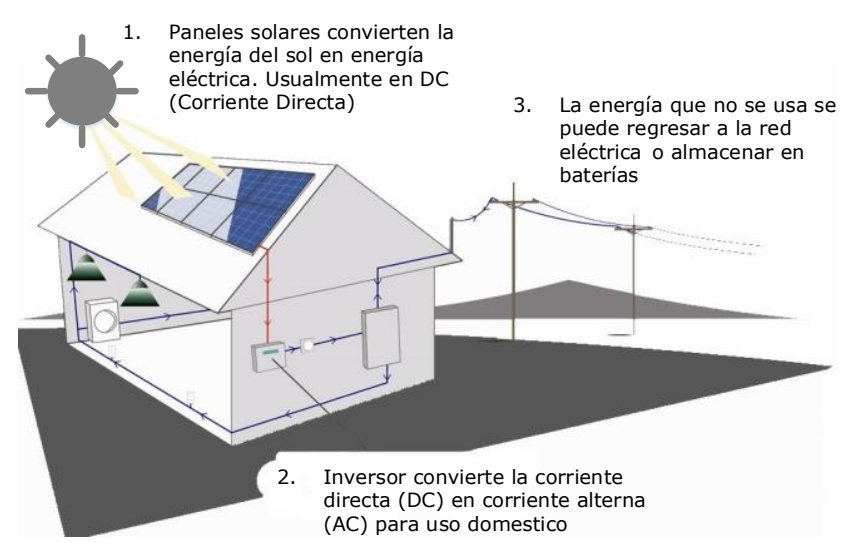

Fig. 4 Solar panel concept in an Arhuaco textbook. Use with permission of the Authors [2].

Unfortunately, more needs to be done to be able to implement the use of radio and transmission of signals such as internet and Wi-Fi. These topics and uses of technology still very limited by the Arhuaco leaders.

\section{The MAth AND EngINEERING OF THE ARHUACO}

Currently composed by a decimal system, from zero (0) to nine (9); although, it is highly probable that the Iku did not have the concept of zero centuries ago. Thus, this could be an adaptation of western numerical systems (See Fig. 5).

It should be noted that interacting and teaching to native communities may require a different approach to those used in urban societies. Not all indigenous communities are equal, their languages, geographical locations and their willingness to accept outsiders will vary from one community to another.

Therefore, adaptation to each group will be essential for the successful implementation of numerical systems in their culture and daily life, as well as ways of documenting their current systems and languages.

In the particular case of the Arhuacos, efforts have been made by the authors and the local education boards to assist the native leaders develop their own curricula. Our main input has been the inclusion of native language and the presentation of other numerical systems widely used by other indigenous communities throughout Latin America. Those additional numerical systems include vigesimal systems by the Maya and Aztec, the Inca's decimal system, as well as binary systems used in modern computers.

In early 2019, it is our intent to complete the next stage on the ongoing effort revising their educational plans.

\section{Arhuaco Numbers (Pronunciation in Chibcha Language):}
1. (Ingui)
2. (Mouga)
3. (Mayk $\because n \forall)$
4. (Ma'keywa)
5. (Asewa)
6. (Chingwa)
7. (Koga)
8. (Abewa)
9. (Ikawa)
10. (Uga)
11. (Ingui uga ingui kधtoy) o $((1 \times 10)+1)$
12. (Ingui uga mouga k甘toษ) o $((1 \times 10)+2)$
13. (Ingui uga mayk $\uplus n \uplus$ k $\forall$ to $)$ o $((1 \times 10)+3)$
14. (Ingui uga ma'keywa kもtoy) o $((1 \times 10)+4)$
15. (Ingui uga asewa kytoy) o $((1 \times 10)+5)$
16. (Ingui uga chingwa kधtoษ) o $((1 \times 10)+6)$
17. (Ingui uga koga k甘toษ) o $((1 \times 10)+7)$
18. (Ingui uga abewa kもtoษ) o $((1 \times 10)+8)$
19. (Ingui uga ikawa kytoy) o $((1 \times 10)+9)$
20. (Mouga uga) o $(2 \times 10)$

Fig. 5 Iku's Numbers [1].

\section{The Math of the Maya And AzTECS: MayA ABACUS OR NEPOHUALTZINTZIN}

Both the Aztecs and the Maya used similar calculation tools based on the vigesimal system (base 20), although with slightly different applications on their calendars.

The Maya abacus or Nepohualtzintzin consists of a grid made with rods and seeds that represent the numbers, as needed. In the lower part there are four counts, which in the first row have unit values (or 1, 2, 3, and 4), and in the upper part there are three counts, with values of five units (or 5, 10, and 15), respectively. The counts in the additional columns have assigned values depending on the numerical system in base 20, as shown in Fig. 6.

For the Maya and Aztecs, counting in base 20 was completely natural, since the use of sandals allowed them to use their toes, as well as their fingers, to count and make calculations. 


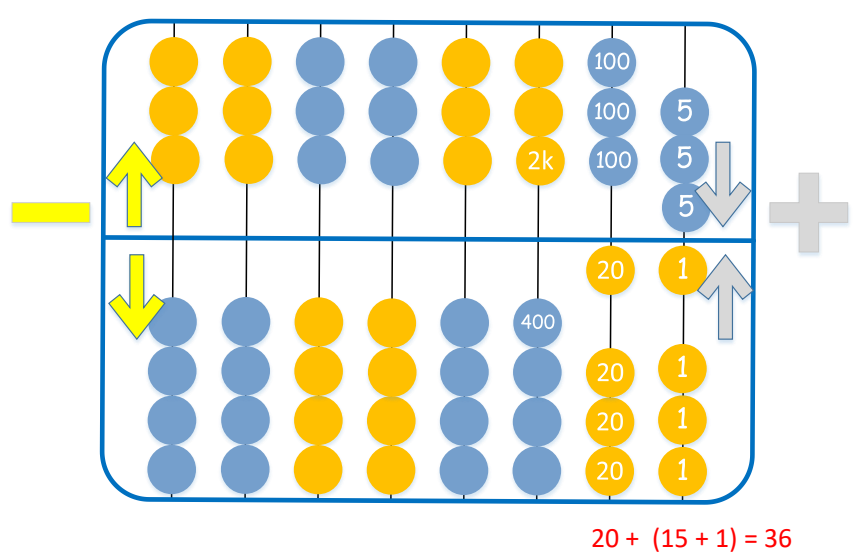

Fig. 6 Nepohualtzintzin (Maya Abacus) [1].

A complete Maya abacus would have 13 rows with 7 counts in each row, representing 91 counts in each Nepohualtzintzin. This number, 91, is fundamental to understanding the close relationship between the Maya and natural phenomena they observed. For example:

1 Cycle $(91)=$ Number of days in each season of the year

2 Cycles $(182)=$ Number of days of the corn cycle

3 Cycles (273) $=$ Number of days of gestation of a baby

4 Cycles (364) = approximately one year

It is important to mention that in the Maya abacus, both huge quantities and small infinitesimal measurements can be calculated with absolute precision.

\section{IMPACT ON CURRENT NUMERICAL SYSTEMS AND APPLIED SCIENCE}

It is important to highlight that the current Gregorian calendar and binary code can use some improvements. For example, Pope Gregory VIII only corrected the current globally used calendar in 1582 and it was only adopted in the new world in 1752. The Pope basically corrected the Julian calendar by adding leap years every four years except in those years when a new century begins (1900, 2000, etc...) unless 400 cannot evenly divide the new century's number. This is more of a mathematical adjustment, but it works very well. For example, the year 1900 was not a leap year $(1900 / 400=4.75)$, but the year 2000 was a leap year $(2000 / 400=5)$. This adjustment by Pope Gregory VIII has an accuracy of approximately sixteen seconds per year. This is why we still use it today.

In binary code, the numerical system in base 2 or binary abacus uses a series of parallel wire beads arranged in three different rows. The accounts represent a change of action in the sequence, either in the form of One (1) or "on-ignition;" or in the form of zero (0) or "off-off."

Amazingly, this type of abacus is the basis for the technology used in computers today. This numerical system represents any number, letters, words, signs, and commands as a combination of ones and zeros that can be stored and used on computer languages or through the ASCII programming language (see Fig. 7).

Computers can only understand numbers, so ASCII is the numerical representation of any character such as 'a' or '@' or 'numbers' or any action or command of any kind.

Imagine what could happen if we use the system in base 20? Or any other numerical system used by indigenous people where several more options could be leveraged to represent the inputs or logic behind the scenes.

For starters, the information that currently takes tens of digits could be represented with far fewer characters, thereby reducing both the amount of memory needed and processing time. The applications would be extremely useful. That is why the Mayan numerical system, or base 20 system, could be a key element for the development of new technologies, managing massive amounts of data, and programing new super computers.

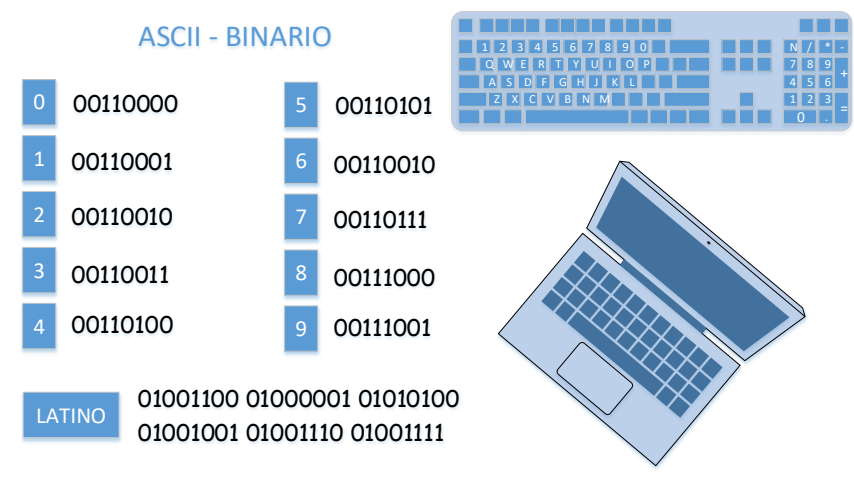

Fig. 7 Binary Code and ASCII Code used in Modern Computers [1].

\section{OTHER IMPORTANT STEM CONCEPTS FOR THE ARHUACO/IKU PEOPLE}

Basic concepts commonly taught in non-indigenous school districts, such as matter and energy, chemistry and astrology, as well as fauna and flora are now been implemented in indigenous curricula. All these combined with their ancestral methodologies and believes, is helping the Iku People to better understand the always changing, fast pace, commonly observed behaviors in outsiders.

Fortunately enough, these indigenous communities have been able to adapt and learn without losing their identity and ethnic values and skills.

Some of those native skills as architects, engineers, and chemists still thought under a complex traditional native law. According to their ancestral believes, all elements on earth have a reason to exist, a purpose to fulfill, and a responsibility to serve others.

Thru generations, they have been able to document the use and values of a diverse array of plants, animals, rocks, water resources and more. For example, there are many plants that serve the construction of houses, bridges, and more, but due to their traditional laws that regulate the use of them, the law determines for example, which species and tools are dedicated to each specific use. 
The same applies to dyes and clothing manufacturing, medicine, and even fruits and vegetables for their nutrition (See Table I).

TABLE I

Edible Plants (Brief List as an Example) [2].

\begin{tabular}{|c|c|c|}
\hline $\begin{array}{c}\text { Name } \\
\text { Za'kinuga }\end{array}$ & $\begin{array}{l}\text { Edible Part } \\
\text { Gukwey } \\
\text { Na'ba }\end{array}$ & $\begin{array}{c}\text { Weather } \\
\text { Inay Uwayke }\end{array}$ \\
\hline $\begin{array}{l}\text { Avocado } \\
\text { Awakati }\end{array}$ & $\begin{array}{l}\text { Fruit } \\
\text { Agucht }\end{array}$ & $\begin{array}{l}\text { Mild } \\
\text { Kumu Zuneku }\end{array}$ \\
\hline $\begin{array}{l}\text { Sugar Cane } \\
\text { Kuñu }\end{array}$ & $\begin{array}{l}\text { Stem } \\
\text { Aktnt }\end{array}$ & $\begin{array}{l}\text { Warm and Mild } \\
\text { Wiwi Awiri Kumt Zunekt }\end{array}$ \\
\hline $\begin{array}{l}\text { Banana } \\
\text { Giñia }\end{array}$ & $\begin{array}{l}\text { Fruit } \\
\text { Agttht }\end{array}$ & $\begin{array}{l}\text { Warm } \\
\text { Wiwi Zuna'ba }\end{array}$ \\
\hline $\begin{array}{l}\text { Lettuce } \\
\text { Rechuga }\end{array}$ & $\begin{array}{l}\text { Leaf } \\
\text { Azachu }\end{array}$ & $\begin{array}{l}\text { Mild } \\
\text { Kumu Zuneku }\end{array}$ \\
\hline $\begin{array}{l}\text { Corn } \\
\text { In }\end{array}$ & $\begin{array}{l}\text { Grain (Seed) } \\
\text { Uwa }\end{array}$ & $\begin{array}{l}\text { Warm and Mild } \\
\text { Wiwi Awiri Kumu Zunekt }\end{array}$ \\
\hline $\begin{array}{l}\text { Mandarine } \\
\text { Mandlarina }\end{array}$ & $\begin{array}{l}\text { Fruit } \\
\text { Agtch } t\end{array}$ & $\begin{array}{l}\text { Warm } \\
\text { Wiwi Zuna'ba }\end{array}$ \\
\hline $\begin{array}{l}\text { Mango } \\
\text { Mangu }\end{array}$ & $\begin{array}{l}\text { Fruit } \\
\text { Agtcht }\end{array}$ & $\begin{array}{l}\text { Warm and Mild } \\
\text { Wiwi Awiri Kumt Zunekt }\end{array}$ \\
\hline
\end{tabular}

Other phenomena like earthquakes and the natural seasons are now also better explained in their own native methods, but with the help of textbooks implementing scientific concepts in their own language or bilingual Spanish/Ikun/Chibcha (See Fig. 8).

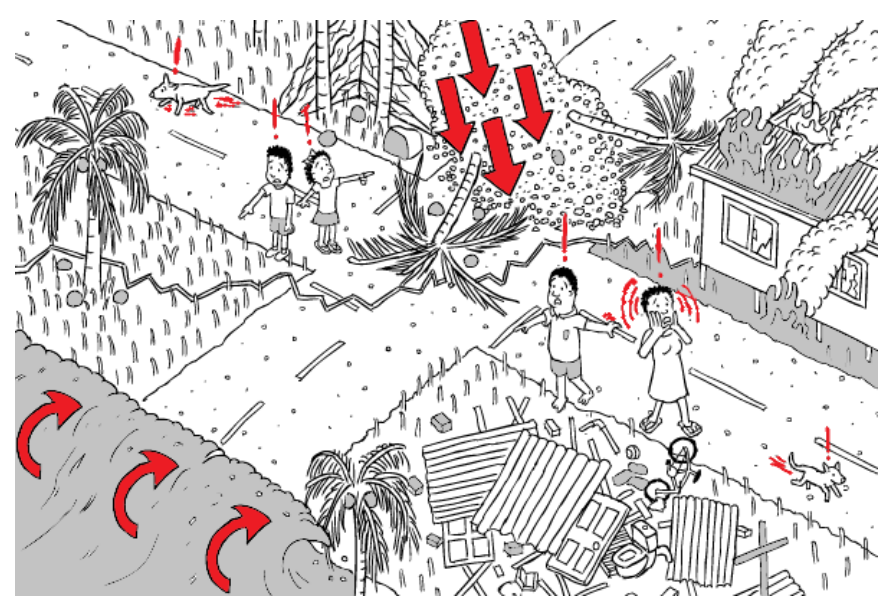

Fig. 8 Earthquake (Seymuke) Illustration [2].

\section{IMPLEMENTATION IN GLOBALIZED CURRICULA AND APPLIED SCIENCE}

If there is a place for indigenous mathematical systems in current educational programs, an effort should be made to include as many references from as many native cultures as possible. Not only would this prevent a perceived bias and be against scientific observation rules, but any exclusions might be damaging to local tribes who see other cultures as their closest ancestors.

Therefore, a conscious effort shall be made to add these cultures and their principles to current educational programs.

Another important element to be considered shall be the language used to present these elements to existing indigenous communities. Using their native language will help achieving multiple goals, including some non-directly related to STEM, such as, preserving cultural and language elements, as well as, humanitarian and educational efforts of helping other communities value ancestral indigenous' way of living and perseverance.

While researching this project, educational systems in multiple countries were consulted. Although more research needs to be conducted, there are obvious areas where this information could be incorporated into current pedagogical methods. Furthermore, since some curriculums have five levels/grades for elementary schools, and others have six, it is reasonable to include the Native American tribes' math and science skills that best fit each program/curriculum. For the most part, forth to sixth grade seems like the ideal time; the math and measuring systems needed usually accompany other STEM activities and skills, thus reinforcing young kid's base knowledge and creativity. It also opens the door for new opportunities to be pursued by local boards of education or individual/regional native schools.

Other uses for native mathematical systems may include tactile and play lessons in counting and computing (i.e., build and practice with a Maya calculator as seen in Fig. 9).

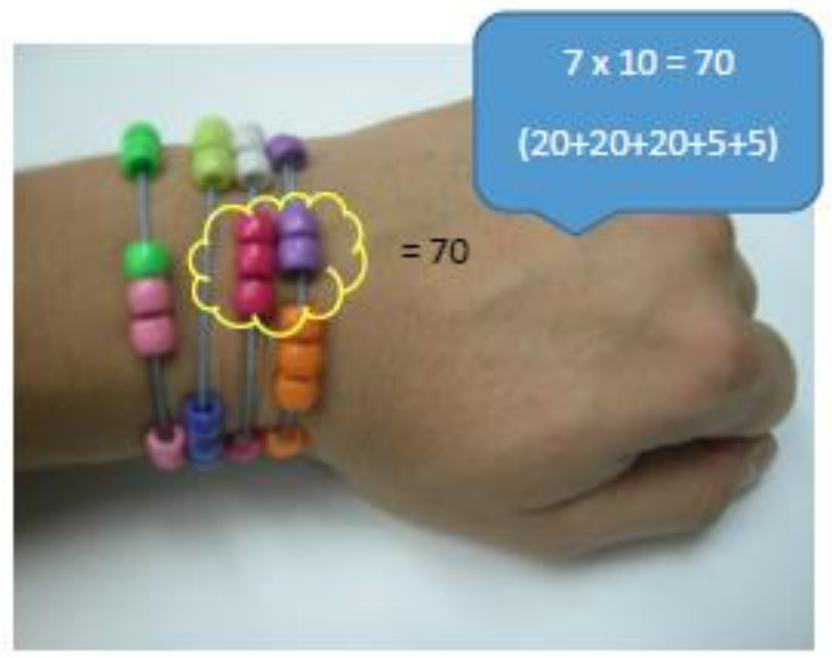

Fig. 9 Maya Calculator [1].

\section{HOW CAN WE HELP OTHER NATIVE TRIBES?}

As mentioned, teaching or even interacting with other native communities in existence today may require a different approach from those used in urbane societies. Not all native tribes are the same, their languages, geographic locations, and willingness to accept outsiders will vary from 
tribe to tribe. Therefore, adapting to each community will be essential for a successful implementation of these numerical systems into their culture and daily life.

Again, these numerical systems and concepts may give those existing tribes a chance to improve their native math skills and overall awareness of other civilizations. Having a documented set of instructions and collected history facts about each approached native community will be a huge add value of further research.

Unfortunately, as mentioned by López \& Sichra [3], the lack of textbooks or multilingual educational material and because the use of a pre-set language (Spanish, in their referenced case) of instructions and schooling systems still prevails, multilingual natives kids may don't find the suitable tools at schools to properly use, at their advantage, the capabilities of their native languages and other skills, including math and analytical wisdom.

López \& Sichra also made reference to teachers, especially those in, or close proximity to, native regions, to be able to communicate in the native language(s), and been able to teach the curriculum(s) not only in the native language but using contextualized examples appropriate for each community.

To such effect, efforts shall be made to translate basic concepts and textbook content into the native language(s) (i.e. use of Chibcha language when in proximity of Arhuaco or Iku natives in Colombia), as well as train teachers on the applicable native language(s).

\section{CONCLUSIONS}

This paper is a simple attempt to raise awareness of some of our magnificent Pre-Columbian Native American tribes/civilizations and their advanced math and applied science skills. It is nothing more than an exercise to conserve, cultivate, and revitalize new STEM skills for human kind, to progress and advance in harmony with nature and other civilizations.

The recommendation to include the numerical systems and their applications in current educational curriculums is simply an attempt to provide a general guidance, and not to be considered as any type of interventionism to the local educational programs, existing tribes and/or their cultures.

Finally, regardless of curriculum acceptance or not, an effort should be made to preserve and promulgate these and other American Native cultures with advanced math skills and applied science; and to explore how integrating them into our current numerical systems can be beneficial to solve technology challenges facing our current and future societies.

\section{ACKNOWLEDGMENT}

We are grateful to all of those with whom we have had the pleasure to work during this and other related projects. We would especially like to thank our families, whose love and guidance are with us in whatever we pursue. Most importantly, We wish to thank the Arhuaco tribe, natives of the Sierra Nevada de Santa Marta, Colombia, for their wisdom and, as they continue to serve as living reminders of our native ancestors.

We would like to thank Melissa Amaral, Higher Education Professional at Rutgers and Princeton Universities, for her review of the Maya artwork. In addition, many thanks to the peer reviewers for their assistance and comments that greatly improved the manuscript, although any errors are our own and should not tarnish the reputations of these esteemed persons.

\section{REFERENCES}

[1] Vega Janica, E. (2018), "Nativo Matemáticas 5", math textbook for kids, Spanish ed. [ISBN: 978-0-9997757-0-7]. "Native Mathematics 56", English ed. [ISBN: 978-0-9997757-1-4].

[2] Vega Janica, E., Vega Murgas, H., Esmeral Ariza, S. (2019), "Iku 4: Ciencia, Naturaleza y Arte del Pueblo Arhuaco", STEM and Historical indigenous textbook for kids, Bilingual Spanish/Iku ed. [ISBN: 978-09997757-2-1].

[3] López, L.E. \& I. Sichra. (2008). "Intercultural bilingual education for indigenous peoples in Latin America". In J. Cummins \& $\mathrm{N}$. Hornberger (eds.) Bilingual Education, Vol 5.Encyclopedia of Language and Education.Second Edition.New York: Springer. Text translated from UNESCO 2015-No.9 Apuntes. Educación y Desarrollo Post-2015, "Educación Intercultural Bilingüe: Educación y Diversidad", by Geraldine Abarca Cariman.

\section{AUTHOR INFORMATION}

Ernesto Vega Jánica, Senior Manager Opportunities Development, Business Development \& Alliance Management, IEEE Standards Association. https://www.linkedin.com/in/ernesto-vega-janica-50231319

Hugues Vega Murgas, Senior Researcher and Author Retired executive Santa Marta's Board of Education.

Simón José Esmeral Ariza. PhD,

Associate Researcher. Colciencias, Quality lead member Santa Marta's Board of Education https://orcid.org/0000-0002-3302-3028 https://orcid.org/sites/default/files/images/orcid_16x16.png 